\title{
San Carlos: Un modelo de conexión social en medio de la violencia
}

\author{
Héctor Fabio Guerrero Berrío* \\ (hector_fabio17@hotmail.com)
}

Artículo corto recibido el 02/10/2015 aprobado el 19/11/2015.

Cómo citar este artículo:

GUERRERO BERRÍO, Héctor Fabio (2015). "San Carlos: Un modelo de conexión social en medio de la violencia". En: Trans-pasando Fronteras, Núm. 8, pp. 85-94. Cali, Colombia: Centro de Estudios Interdisciplinarios, Jurídicos, Sociales y Humanistas (CIES), Facultad de Derecho y Ciencias sociales, Universidad Icesi.

DOI: $10.18046 /$ retf.i8.2121

\section{Resumen}

El presente ensayo analiza la dinámica que ha tenido el conflicto armado en el municipio de San Carlos, Antioquia, desde la última década del siglo XX hasta la actualidad. Específicamente, analiza los daños morales, psicológicos y políticos que han generado las masacres de las veredas El Chocó y Dos Quebradas, así como las acciones de resistencia social que ha realizado la comunidad para la construcción de una nueva realidad en su territorio. Lo anterior sugiere la importancia de comprender el ejercicio de reflexión ética que han realizado las víctimas a partir de la memoria colectiva e individual, para configurar lo que, de acuerdo a la óptica de Iris Young, se denominaría un modelo de conexión social, que les ha permitido asumir responsabilidades colectivas para hacer frente a las injusticias estructurales que han padecido.

* Estudiante de Economía y Negocios Internacionales de la Universidad Icesi. 


\section{Palabras clave}

Ética de la Memoria, Injusticia Estructural, Modelo de Conexión Social, Daños psicológicos, morales y políticos.

\section{Introducción}

El conflicto armado ha sido una realidad para millones de colombianos desde hace más de medio siglo. A lo largo de este periodo, un sinnúmero de actos crueles y de lesa humanidad han atentado contra la integridad de la población, y han ocasionado que millones de personas vivan entre el horror del conflicto, la desesperanza en las instituciones oficiales y la indiferencia de muchos de sus compatriotas. Uno de los casos más representativos del conflicto en nuestro país es el ocurrido en San Carlos, Antioquía, un municipio en el suroriente antioqueño que desde hace tres décadas ha afrontado una secuencia de actos violentos y cuya principal víctima ha sido la población civil.

El presente ensayo tiene como objetivo analizar las acciones violentas ocurridas en el municipio de San Carlos, específicamente en las veredas de Dos Quebradas y El Chocó a finales del siglo XX y los primeros años de la década del 2000, para proponer, de manera crítica, una reflexión sobre la ética de la memoria y la responsabilidad ciudadana en este caso particular de la violencia en Colombia. El esquema metodológico se basa en la revisión de fuentes secundarias, en tanto recopila testimonios de las víctimas y datos relevantes para la comprensión de la dinámica del conflicto, que permiten contrastar, a la luz de la teoría, como la ejecución de mecanismos de conexión social basados en la ética de la memoria logran consolidar un proceso transformación en la comunidad. En este sentido, la tesis propuesta aduce que el conflicto en la zona ha propiciado graves daños estructurales sobre el tejido social de la población, cuyos impactos logran superarse mediante la adecuada articulación de modelos de conexión social que incluyen la participación de diferentes estamentos sociales y la sensibilización ética de los ciudadanos.

En la historia de San Carlos confluyen muchas de las diferentes dinámicas que ha presentado el conflicto a nivel nacional: por un lado, se presenta el auge del movimiento social y revolucionario en la zona a mediados de la década de 1980, manifestado con la aparición de guerrillas insurgentes como las FARC y el ELN; y por otro, emergen grupos paramilitares con grandes pretensiones sobre la población y el 
territorio. Estos eventos ocurren en medio de la tímida reacción de las autoridades locales y en el marco de una región estratégica, dominada por importantes reservas hídricas. La confrontación armada que surgió entre los diferentes grupos insurgentes desencadenó graves consecuencias sobre el tejido social del municipio, y extendió formas diversas de violencia como amenazas, extorsiones, masacres y desplazamientos forzosos. De acuerdo con estadísticas oficiales del Centro de Memoria Histórica (GMH), en San Carlos se presentaron al menos 32 masacres entre los años 1998 y 2005, y en las tres décadas más marcadas del conflicto, se produjo el desplazamiento de casi 25.000 de sus habitantes (CNRR, 2011: 110).

Uno de los episodios de mayor recordación en el conflicto que ha padecido el municipio de San Carlos, es el de las masacres perpetuadas en las veredas de El Chocó y Dos Quebradas en 2002 y 2003 respectivamente. Ambos casos tienen una conexión particular, identificada inicialmente con las pretensiones de dominio territorial por parte de las AUC, y luego motivada por el sentimiento de retaliación de las FARC. De acuerdo con información de la prensa, el 22 de noviembre de 2002 integrantes de las AUC ingresaron a la vereda El Chocó, donde asesinaron entre 8 y 11 campesinos. Cada uno de ellos fue asesinado en lugares públicos, y sus cuerpos quedaron totalmente desfigurados (CNRR, 2011: 124).

Asimismo, según la información de la administración municipal de San Carlos, la acción violenta de las AUC ocasionó el desplazamiento masivo de alrededor de 300 personas (CNRR, 2011: 124), un fenómeno que se constituyó como un éxodo masivo en una población previamente menguada por el conflicto. Por su parte, el día 16 de enero de 2003, a menos de dos meses del acontecimiento anterior, se presentó una nueva masacre en las veredas de Dos Quebradas, la Tupiada y Dinamarca, que sumaron en total 18 personas. La autoría de este hecho fue reconocida tiempo después por las FARC, quienes justificaron su acción como retaliación a la perpetrada previamente por las AUC. En el hecho, varios hombres armados del frente IX del grupo guerrillero penetraron en la vereda y asesinaron a 11 personas, entre las que se encontraban siete menores de edad. Luego, en La Tupiada y Dinamarca, asesinaron a otras siete personas, muchas de ellas degolladas.

Con respecto a estos acontecimientos, una de las mujeres testigo de los acontecimientos relata así lo sucedido: 
"Cuando yo vi que por la parte de arriba llega gente armada y también por la parte de abajo, me entré con mi niño de siete años (...) Cuando cesaron los disparos nos encontramos un muerto, y otro, y otro más. Cuando llegamos a la casa estaban los jovencitos, tirados en un charco de sangre que parecía una piscina. Vemos uno a uno horrorizados y de pronto descubro a mi niño en un extremo del corredor. Yo sentí como si el tiempo retrocediera, ahora este dolor tan inmenso me desagarró todo" (CNRR, 2011: 126).

En este caso, la mujer sufre los efectos devastadores de la violencia, y se constituye como una víctima directa del conflicto, pues afronta la pérdida de su hijo y las desgarradoras consecuencias que viven sus coterráneos, afectando su cosmovisión personal y social.

Los actos violentos cometidos en contra de la población de San Carlos, y en particular, las masacres de las veredas de El Chocó y Dos Quebradas, han ocasionado incalculables daños en las víctimas directas e indirectas del conflicto. En primer lugar, los habitantes del municipio se han visto expuestos a daños morales, que se definen como aquellas consecuencias lesivas que afectan el buen nombre, la dignidad y la reputación de las víctimas, alterando sensiblemente la autoestima y los sentimientos de valía de las personas (CNRR, 2011: 266). Estos daños morales han afectado a la comunidad en la medida que se ha visto expuesta tanto a la confrontación armada directa, como al proceso de desplazamiento de la población civil, que fue sometida a una serie de abusos, tratos inapropiados y situaciones humillantes que comprometieron seriamente su dignidad. Lo anterior también ha alterado en gran medida la autoestima de muchas de las víctimas y ha contribuido a menoscabar sus valores más significativos.

Por su parte, los daños psicológicos que se desprenden del conflicto analizado incluyen las situaciones de terror intenso, así como las de profundo miedo, a la que se expuso la población, permanentemente amenazada por los grupos armados, y que se encontraba en estado de completa indefensión. De acuerdo con las investigaciones adelantadas por el GMH, los sentimientos de miedo y pánico son los que la población más refiere, e incluso en la actualidad se vuelven a manifestar en sus cuerpos señales de dolor a través de temblores, sudores y palpitaciones (CNRR, 2011: 257).

Por último, se encuentran los daños políticos, que son exacerbados con las múltiples confrontaciones armadas que había vivido el municipio hasta entonces. Las masacres 
ocurridas incluyeron el asesinato de líderes sociales, que eran llamados a ser protagonistas de nuevas dinámicas de desarrollo económico y actores principales de una nueva apuesta política. Con la desaparición de muchos de sus líderes sociales más representativos se generó un daño inmaterial irreparable sobre la población sancarlitana, que contribuyó a inhibir la participación ciudadana en las decisiones públicas y en la denuncia de irregularidades, así como la organización y oposición política A su vez, la ineficiencia en muchos casos del sistema judicial, y la imposibilidad de una reparación efectiva, ha contribuido a deslegitimar el papel de las instituciones oficiales, ocasionando una falta de credibilidad y apatía con relación a la participación en la esfera pública.

Ahora bien, para comprender el origen del conflicto armado en el municipio de San Carlos es necesario recurrir al concepto de injusticias estructurales, pues su causa no se puede atribuir a un grupo o actor en particular, sino a un conjunto de ellos, entre los que se encuentran los Grupos Armados, cuya lucha por el territorio ha involucrado a la población civil como principal víctima, el Estado, que no propició las condiciones mínimas de seguridad y protección para los habitantes, la Fuerza Pública, que en muchas ocasiones no reaccionó oportunamente ante las atrocidades, e incluso los mismos habitantes, que en medio de la zona gris del conflicto, optaron por integrarse a los grupos insurgentes o colaborar con ellos.

Asimismo, las consecuencias del conflicto también han generado otra serie de injusticias estructurales con las víctimas directas e indirectas del mismo. Esto se puede evidenciar en las memorias de los desplazados, quienes tuvieron que huir del horror de la guerra y refugiarse en zonas donde, la mayoría de las veces, no fueron bien recibidos. Lo anterior, sumado a los daños psicológicos y morales producidos directamente por la confrontación, ha generado un sinnúmero de consecuencias que afectan el proyecto de vida de las víctimas, así como sus propias convicciones y sentimientos.

No obstante, la dinámica misma del conflicto también ha propiciado la aparición de actos de resistencia por parte de las víctimas, a pesar de las graves consecuencias que ha tenido el conflicto sobre el municipio. La estrategia de resistir al dominio se constituye como un conjunto de acciones de confrontación, desobediencia civil y oposición a la hegemonía de los grupos armados en la región, y en este sentido, los habitantes de San Carlos han desarrollado acciones colectivas de resistencia que, de acuerdo a la definición de Young, se constituyen como verdaderos modelos de conexión social, para transformar la realidad 
del entorno y reducir las consecuencias del conflicto que tanto ha menguado a la población.

Algunas de estas acciones, de acuerdo con investigaciones del GMH, incluyen la interpelación a las listas de muerte; las negociaciones y reclamos individuales frente a frente con los grupos armados; las acciones de desafío ideológico; las marchas y las denuncias en medio de la guerra, entre otras (CNRR, 2011:290), que vinieron ejecutándose en la población a medida que el conflicto se recrudecía y contribuyeron a sentar, paulatinamente, los precedentes de liderazgo y resistencia de la comunidad para la construcción de paz en el territorio y la defensa de los derechos humano. Actualmente, el municipio de San Carlos es un territorio en reconstrucción, que ha experimentado el proceso de retorno de las víctimas y desplazados de forma acelerada a partir de 2008, y que tiene plena convicción en la construcción de un futuro distinto, en el que la nueva generación sea abanderada de la paz, la tolerancia y la convivencia como pilares sociales fundamentales, a pesar de las huellas indelebles que la violencia ha dejado en la memoria de la comunidad.

En el contexto de las consecuencias y daños que ha ocasionado el conflicto en la población de San Carlos, el ejercicio de la memoria individual y colectiva de las víctimas se constituye como una actividad fundamental para develar las injusticias sistemáticamente infringidas por los grupos armados, e incluso, por la fuerza pública. Cada uno de sus testimonios se convierte en una herramienta valiosa para evaluar las acciones del pasado, comprender la verdad, y pensar en un futuro de justicia y reparación para las víctimas. En este sentido, una ética de la memoria para el caso de las masacres de Dos Quebradas y El Chocó en San Carlos, permite la construcción de las nuevas convicciones y aspiraciones de los habitantes, basadas en las experiencias del pasado.

Sin embargo, para comprender la aplicación de la ética de la memoria como mecanismo eficiente para la superación de la violencia del municipio de San Carlos y la transformación de la realidad en la vida de sus habitantes, es necesario delimitar tanto su alcance como su conceptualización. De acuerdo con Héctor Schmucler, la memoria es la práctica de una ética que está antes del hacer y de la historia, pero que sólo se refleja en las acciones concretas de ese hacer (Schmucler; 2005). Por tanto, de acuerdo a la perspectiva del autor, la ética de la memoria implica una reflexión crítica sobre los acontecimientos acaecidos en un momento particular, con el objetivo de obrar, involucrando creencias sobre las acciones y asumiendo actitudes que las llenan de sentido. 
Así pues, la memoria, aunque múltiple y conflictual, puede permitir a las comunidades hacer visibles los actos que las afectaron en el pasado y ejecutar mecanismos importantes que permitan modificar esa realidad.

En el caso del conflicto en San Carlos, la memoria que guardan las víctimas remite en varias oportunidades a determinadas creencias y valores, las cuales implican un hacer y un deber hacer frente al contexto de violencia generalizada, desplazamientos forzados y zozobra constante. En este sentido, la reflexión sobre la memoria es un ejemplo de ejercicio ético, que implica un sistema de valores diferentes y aconseja una conducta influyente sobre el actuar de la comunidad.

Asimismo, de acuerdo con Hugo Vezzetti, "la memoria es plenamente histórica y está sometida al conflicto y a las luchas de sentido" (Vezzetti, 2002: 33, 34). En consecuencia, el autor sostiene que no hay ni memoria plena ni olvido logrado, sino más bien diversas formaciones que suponen un compromiso de la memoria y el olvido (Vezzetti, 2002: 33). Por lo tanto, siguiendo la idea del autor, el ejercicio de la memoria histórica por parte de los sancarlitanos permitió la configuración de un compromiso explícito por transformar la realidad violenta del contexto, mediante la articulación de modelos de conexión social, que a su vez impiden olvidar los acontecimientos que durante años afectaron a la comunidad.

Por su parte, siguiendo Maliandi, el ejercicio de reflexionar sobre la memoria consiste también en "investigar, ponerse en la huella, o rastrear algo" (Maliandi, 2009: 25), lo cual permite comprender las acciones que se toman por parte de la comunidad en el sentido de una memoria que en otros tiempos se recordó. En el contexto del conflicto y las consecuencias que afrontó la población, la huella de la memoria y su significación es fácilmente rastreable en sus acciones: las víctimas lograron más allá de recordar y vivenciar los horrores de la violencia entender como sus mecanismos de resistencia podrían cambiar el curso de su comunidad, en un proceso de reconstrucción de la memoria histórica y colectiva.

Por esta razón, la memoria, de acuerdo a los diferentes puntos de vista analizados en este ensayo, no es sólo una fuente de la historia, sino que es fundamentalmente un indispensable impulso moral y, además, es un deber y una necesidad ética y política de la sociedad, que fue aplicada con éxito por parte de la comunidad de San Carlos para superar las consecuencias del conflicto a través de sus mecanismos de resistencia. 
De acuerdo con lo anterior, la reflexión ética de la comunidad de San Carlos permitió aplicar el concepto de memoria, rememorando todo aquello que por muchos años se dejó de lado a la hora de recordar, y también permitió identificarla como una construcción que conduce a generar mecanismos de conexión social. Este concepto, además, dio lugar a la hegemonía de otro sistema de valores, que reivindican la lucha por la defensa y el respeto derechos humanos de los sancarlitanos, por años afectados por las consecuencias de la violencia.

En síntesis, en el caso del conflicto de San Carlos, la reflexión ética sobre la memoria implicó no solo el deber de recordar, sino también de valorar el pasado por un presente ansioso de justicia Por tanto, hablar sobre la ética de la memoria en este contexto implica reflexionar sobre el conjunto de reglas, normas y valores al que la significación del conflicto ha dado lugar, y tomar acciones encaminadas a modificar es realidad mediante mecanismos de conexión social.

Por otra parte, la definición de ética y su distinción de la moral también adquiere en este contexto una gran importancia para entender la generación de modelos de conexión social. Siguiendo a Cortina, la ética corresponde a la reflexión profunda sobre el conjunto de normas y conductas imperantes en la sociedad, y se fundamenta en la preocupación por el bien de los hombres concretos (Cortina, 2000: 18). Por su parte, el concepto de moral, de acuerdo con Cohen, se suele caracterizar como el conjunto de normas y conductas predominantes en una sociedad dada, que, sin embargo, también puede ser impuesta (Cohen, 2011: 16).

Si se tiene en cuenta lo ocurrido en San Carlos, se puede comprobar que los valores morales de la población podrían haber sido distorsionados en función de los preceptos impuestos por los grupos armados, quienes finalmente decidían las acciones que se debían ejecutar en muchos aspectos. Sin embargo, una reflexión crítica de estas acciones por parte de un grupo de ciudadanos, mediante el pleno ejercicio del análisis ético, permitió emprender modelos de conexión social como los que se gestaron en el municipio frente a la violencia de los grupos armados.

Al incorporar en esta definición el concepto de memoria colectiva, se tiene que la ética, en cuanto reflexión crítica de los acontecimientos sucedidos, debe poner su acento sobre las múltiples narraciones que configuran la identidad de 
las víctimas del conflicto. Desde la ética de la memoria, además, se plantea la necesidad de que la población se sienta en deuda con las víctimas que ha dejado el conflicto y comprometida con los acontecimientos aún no resueltos. Esta motivación es necesaria para construir la memoria colectiva, que permita incentivar los modelos de conexión social, de acuerdo con la perspectiva de Young (2011: 108), no sólo para superar las consecuencias del conflicto, sino para plantear las reivindicaciones futuras.

En conclusión, la existencia de casos de resistencia y cooperación, así como de apropiación del concepto de ética que se han gestado en la población San Carlos, ha propiciado la aparición de modelos de conexión social, que han permitido construir una nueva realidad para el municipio, a pesar de las injusticias estructurales que han sido ocasionadas por las acciones violentas. Lo anterior confirma la necesidad de continuar con estos esfuerzos de compromiso ciudadano para generar modelos que transformen la realidad de las víctimas y permitan la reivindicación de sus derechos. Estos esfuerzos deben provenir de la acción de todos los estamentos sociales, que les exige asumir un rol más participativo de la realidad y hagan frente a la apatía ética, mediante la reflexión crítica de sus acciones, los testimonios de la memoria y la realidad del contexto particular. Estos elementos, en su conjunto, desempeñan un papel trascendental para conseguir la reivindicación de los derechos de la población, asegurar la reparación de las víctimas y garantizar que hechos similares no volverán a ocurrir en el futuro.

\section{Bibliografía}

CNRR - Grupo de Memoria Histórica (GMH) (2011) San Carlos: Memorias del Éxodo en la Guerra, ediciones Semana, Bogotá.

COHEN, Diana A. (2011). Inteligencia ética para la vida cotidiana, Penguin Random House Grupo Editorial Argentina, Buenos Aires,.

CORTINA, Adela (2000). Ética mínima, $6^{\circ}$ edición, editorial Tecnos S.A., Madrid.

MALIANDI, Ricardo (2009). Ética: conceptos y problemas, Ed. Biblos, Buenos Aires.

SCHMUCLER, Héctor (2005). Conferencia pronunciada en la Biblioteca Nacional 
en el marco del ciclo "Pensamiento Contemporáneo". Publicado en: http://laintemperie. com.ar/index/index.php?option=com_content\&task=view\&id=16\&Itemid=31. Consultado el día 30 de enero de 2016.

VEZZETTI, Hugo (2002). Pasado y presente: Guerra, dictadura y sociedad en la Argentina, Buenos Aires, Ed. Siglo XXI.

Young, Iris M. (2011). Responsabilidad por la Justicia, editorial Morata, Madrid. 